\title{
Rail Vehicle Vibrations Control Using Parameters Adaptive PID Controller
}

\author{
Muzaffer Metin and Rahmi Guclu \\ Department of Mechanical Engineering, Yildiz Technical University, Besiktas, 34349 Istanbul, Turkey \\ Correspondence should be addressed to Muzaffer Metin; mmetin@yildiz.edu.tr
}

Received 26 February 2014; Accepted 7 April 2014; Published 29 April 2014

Academic Editor: Weichao Sun

Copyright (C) 2014 M. Metin and R. Guclu. This is an open access article distributed under the Creative Commons Attribution License, which permits unrestricted use, distribution, and reproduction in any medium, provided the original work is properly cited.

In this study, vertical rail vehicle vibrations are controlled by the use of conventional PID and parameters which are adaptive to PID controllers. A parameters adaptive PID controller is designed to improve the passenger comfort by intuitional usage of this method that renews the parameters online and sensitively under variable track inputs. Sinusoidal vertical rail misalignment and measured real rail irregularity are considered as two different disruptive effects of the system. Active vibration control is applied to the system through the secondary suspension. The active suspension application of rail vehicle is examined by using 5-DOF quarter-rail vehicle model by using Manchester benchmark dynamic parameters. The new parameters of adaptive controller are optimized by means of genetic algorithm toolbox of MATLAB. Simulations are performed at maximum urban transportation speed $(90 \mathrm{~km} / \mathrm{h})$ of the rail vehicle with $\pm 5 \%$ load changes of rail vehicle body to test the robustness of controllers. As a result, superior performance of parameters of adaptive controller is determined in time and frequency domain.

\section{Introduction}

Guided rail systems cause vibrations that affect passenger comfort significantly. With the development of technology, the expected comfort level is increased for passengers. Nowadays, while travelling by rail vehicles, passengers have high levels of expectations for comfort with safety. An excellent isolation of rail roughness caused vibration and shock from passengers cannot be provided by using only mechanical solutions on suspension systems. To improve suspension performances, an additional system which can make autonomous decisions actively is needed. In the recent past, combining active vibration control mechanism with suitable control algorithms to fully meet passenger expectations is a requirement in this way.

While minimizing vibrations, there are some considerations to take into account: ride comfort, which is related to accelerations of body vibration; ride safety, which means ensuring the permanence of wheel-rail contact; suspension clearance; and actuator forces. However, these performance requirements are not always compatible; for example, required control force to achieve the desirable ride comfort can create a negative effect on the vehicle's stability. Regarding this, active controlling of rail vehicle vibrations has become a serious engineering problem.

Active suspension consists of sensors, controllers, and actuators, which apply control forces to the vehicle body. The responses of a passive system to track inputs or other disturbances are obtained by using parameters such as inertia, spring, and damping. However, the response for an active suspension system is developed by using an advanced control algorithm. Because of varying rail irregularity, effective solution of this problem is using an adaptive control algorithm to suppress rail vehicle body vibration.

In not only this but also many other studies, quarter vehicle model is used due to its simplicity and convenience. In rail vehicle model, the interaction between wheel and rail is not linear [1], but the interaction model is considered as a simplified linear solution using Hertz spring $[2,3]$. On the other hand, Dukkipati and Dong study the wheel-rail contact, which is modeled as a multispring contact [4]. Lei and Noda model and analyze rail vehicle and railway dynamics using 
the conventional Hertz formula in coupling vehicles and railway tracks [5].

In the last fifteen years, there are notable studies on the active control of vibrations on railway vehicles. Foo and Goodall apply active controller to the rail vehicle secondary suspensions to minimize vertical accelerations of vehicle body [6]. Detailed information about mechatronic developments for railway vehicles is given by Goodall and Kortüm [7]. Güçlü investigates the dynamic behaviour of a nonlinear 8-DOF vehicle model having active suspensions and a PID controlled passenger seat [8]. Ahmadian and Mohan provide a methodology for improving hunting behaviour in rail vehicles by semiactive control of suspension elements [9]. A sliding mode control (SMC) method to improve the ride comfort of a railway vehicle with a flexible body is represented by Yagiz and Gursel [10]. Lin et al. present an application of active suspension controllers for light rail vehicles with the aim of providing superior ride comfort within the suspension stroke limitations [11]. Skyhook damping and linear quadratic Gaussian (LQG), optimal control techniques were considered and the results are compared to improve ride quality of a twoaxle railway vehicle by a number of authors [12]. Orvnäs et al. investigate the effect of active lateral secondary suspension to improve passenger comfort in their experimental study about green train project $[13,14]$. Bruni et al. discuss how primary and secondary suspension models can be obtained and their use for railway vehicle dynamics multibody simulations [15].

In recent years, significant theoretical and implemental studies have been done on the vehicle suspension control strategies. Sun et al. present very significant developments on active suspension control by using $H_{\infty}$ norm on a quarter car model. To improve ride comfort, the $H_{\infty}$ norm from the disturbance to the controlled output is decreased in specific frequency band by using the generalized KalmanYakubovich-Popov (KYP) lemma [16]. Also, this problem is considered to take into account the actuator delay by Sun et al. [17]. On the other hand, to control vehicle vibrations, semiactive suspension system and two comparable control algorithms are used by Lozoya-Santos et al. [18]. With the aim of extending the working time of suspension system and improving ride comfort, an optimal control approach which is based on the active suspension vibration control devices is carried out by Liang and Wu [19].

Besides, there are several studies on active vibration control using fuzzy logic controller. Rao and Prahlad carry out a prestudy on rail vehicles by applying an adjustable fuzzy logic controller [20]. In another study, FLC and conventional PID controller performances are compared using 11 degrees of freedom half-rail vehicle model with sinusoidal rail disturbance [21]. A fuzzy control application is achieved on a LRT system in use in Istanbul traffic by using real parameters [22]. Furthermore, secondary suspensions of rail vehicle are controlled actively by using a conventional PID control and FLC to improve the passenger comfort comparatively. The vertical motions of railway vehicle body and passenger seats are investigated at $140 \mathrm{~km} / \mathrm{h}$ operating speed on random rail irregularity. All parameters of both controllers are achieved by the use of genetic algorithm for the same simulation condition and performance criteria. In conclusion, the ride

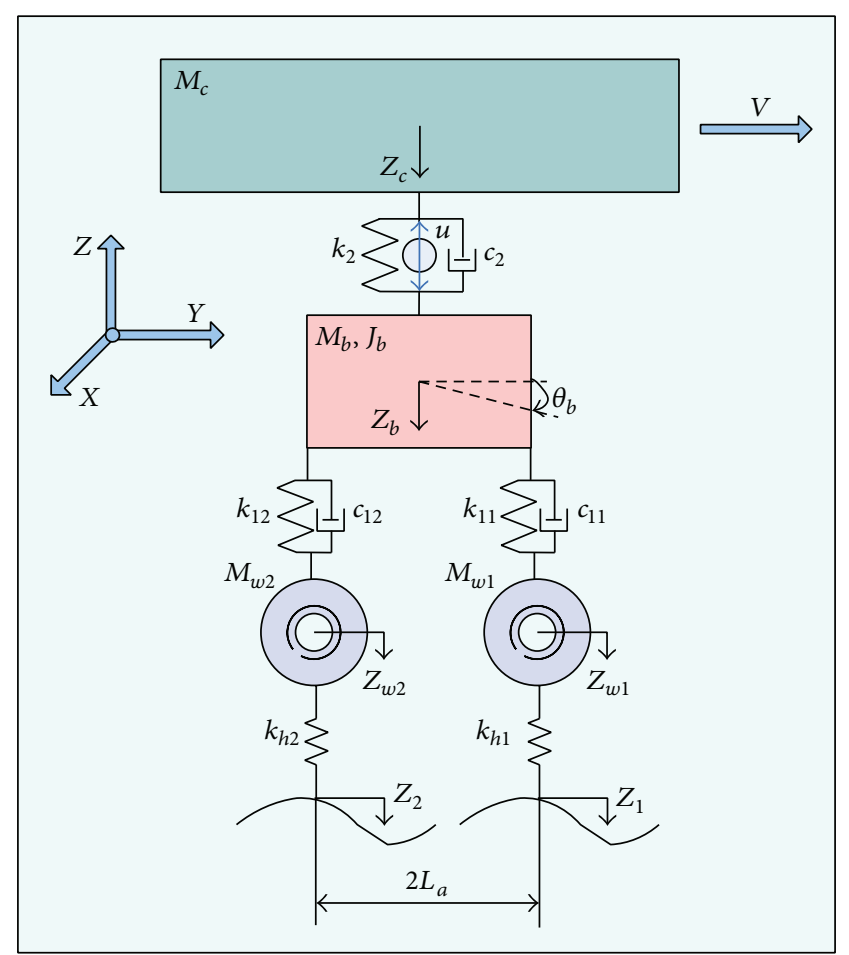

FIGURE 1: The quarter rail vehicle model.

comfort is improved greatly by adding an intelligent FLC between the rail vehicle body and bogie [23].

The focus of this paper is to improve the PID control performances by using an adaptive method which regulates PID parameters online with additional scaling factors. Genetic algorithm can be performed to find the optimum parameters of PID controller which is used in industry widespread. In fact, the obtained parameters are optimum for just actual situation, and the controller can lose its effectiveness under varying rail irregularity condition. However, the adaptive controller system, which is used in this study, adjusts the parameters itself simultaneously according to the varying rail irregularity. With these features, this study distinguishes itself from other prevalent studies.

In this study, active control will be implemented through the secondary suspension system which is located between vehicle body and bogie. For this purpose, rail vehicle is modeled as 5 degrees of freedom which consists of vehicle body, bogie, primary and secondary suspensions, and two wheelsets. A quarter rail vehicle model is designed by using Manchester Benchmark dynamic parameters. The vertical rail vehicle vibrations are controlled by the use of conventional and parameters adaptive PID controllers. A combination of varying loading conditions and robustness of controllers are examined under different rail irregularities. In addition, time and frequency domain responses are investigated under varying loading conditions. As a result of this paper, when control algorithms are compared under the same dynamic conditions, superior performances of adaptive PID controller can be seen in time and frequency domain. 

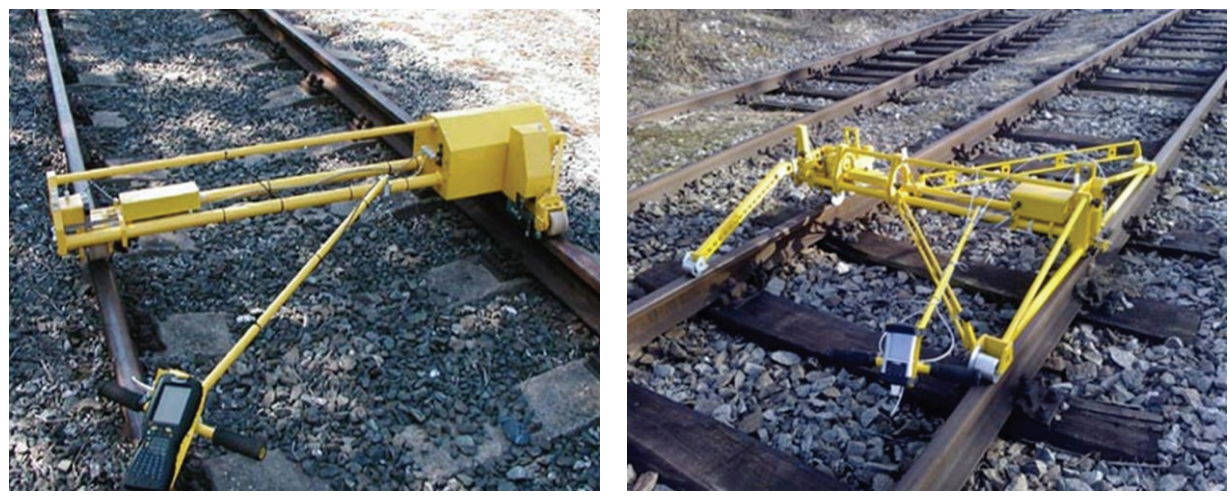

FIgURE 2: KRAB measurement systems.

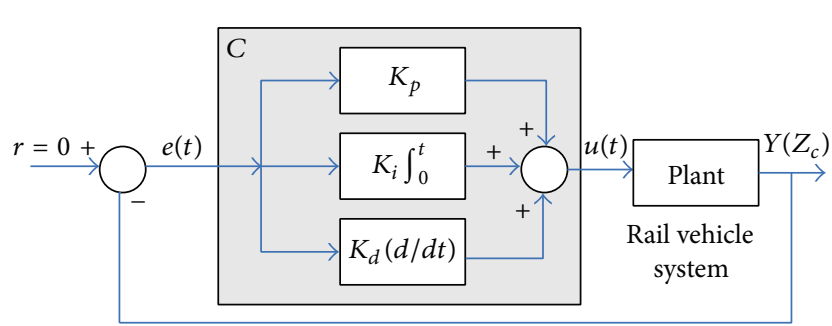

Figure 3: Conventional feedback PID control system.

\section{Dynamic Model of Rail Vehicle}

The quarter rail vehicle model is used in this study (Figure 1). Uncontrolled system inputs are load changes and rail irregularities which can make the system unstable. System outputs are displacement and acceleration of the vehicle body. Passive system response depends on parameters such as mass, spring, damping ratio, and suspension geometry. Active suspension structure is a more complex dynamic system than passive suspension. Performance of the active suspension depends on sensors, actuators, and hardware and software of controller.

Quarter rail vehicle model contains $M_{c}$ which is mass of rail vehicle body, $M_{b}$ which is mass of bogie, $J_{b}$ which is inertia moment of bogie, and $M_{w 1}, M_{w 2}$ which are masses of wheelsets that are located under bogie. $k_{2}$ and $c_{2}$ are secondary suspension stiffness and damping coefficients, respectively. $k_{11}, k_{12}$ and $c_{11}, c_{12}$ are stiffness and damping coefficients of primary suspension. $k_{h 1}$ and $k_{h 2}$ are expressions of the wheel-rail linear contact form of Hertz spring stiffness. The control force $u$ is generated by an actuator which is placed between rail vehicle body and bogie. The half distance between front and rear wheelsets is presented by $L_{a}$ and $V$ is the velocity of rail vehicle. All these parameter values are given in the Appendix.

Generalized coordinates of the system $Z_{c}, Z_{b}, \theta_{b}, Z_{w 1}$, and $Z_{w 2}$ represent the vertical displacement of vehicle body and bogie, the pitch motion of bogie, and the vertical displacements of front and rear wheelsets, respectively. Differential equations of rail vehicle are obtained by using Lagrange's equation. Differential equation of the system is

$$
[M] \ddot{Z}+[C] \dot{Z}+[K] Z=F_{Z}+F_{u} \text {, }
$$

where $Z=\left[Z_{c}, Z_{b}, \theta_{b}, Z_{w 1}, Z_{w 2}\right]^{T}, F_{Z}=$ $\left[\begin{array}{llllll}0 & 0 & 0 & K_{h 1} Z_{1} & K_{h 2} Z_{2}\end{array}\right]^{T}$, and $F_{u}=\left[\begin{array}{lllll}u & -u & 0 & 0 & 0\end{array}\right]^{T}$.

$F_{z}$ is real rail disturbance that causes vibrations. These disturbances act on rail vehicle via rigid wheels. $F_{u}$ is a force that is applied by an actuator. $[\mathrm{M}],[\mathrm{C}]$, and $[\mathrm{K}]$ are mass, damping, and stiffness matrices, which are, respectively, given in the Appendix. $Z_{1}(t)$ and $Z_{2}(t)$ are rail irregularity inputs applied to wheel masses.

During the interaction of rail and wheel, induced forces are transmitted by rail-wheel contact area. Due to the geometry of contact area between rail and wheel, for the wheelrail dynamic interaction, the relationship between the force and deflection is defined by the Hertz contact spring. Hertz contact spring is not a linear contact and depends on the relationship between contact force and deflection of wheelrail contact surface $(y)$. This expression [2] is given in (2). In this equation, $\mathrm{C}_{h}\left[\mathrm{Nm}^{-3 / 2}\right]$ is Hertz contact coefficient which depends on wheel radius, rail radius, and material; $F$ represents static wheel load. Hertz contact spring is defined as a linear spring. Rigidity of Hertz contact linear value $\left(K_{h}\right)$ can be obtained from static wheel load depending on the force-displacement relationship. This is represented by the following equation (3) [3]:

$$
\begin{gathered}
F=C_{h} \cdot y^{3 / 2}[N], \\
K_{h}=\frac{d F}{d y}=\frac{3}{2}\left(C_{h}^{2 / 3} \cdot F^{1 / 3}\right)\left[\frac{N}{m}\right] .
\end{gathered}
$$

The values of the parameters static wheel load $(F)$ and Hertz contact coefficient $\left(C_{h}\right)$ are given in the Appendix.

\section{Measurements of Rail Irregularity}

In this study, in order to measure real rail irregularities, KRAB track geometry measurement system, shown in Figure 2, is used. KRAB is a complete track geometry measurement system [24]. Istanbul Transportation Co. uses this system to measure deviation from the initial design geometry of railway superstructure. This measurement system is a trolley that can be pushed or pulled by an operator. A GPS module can be equipped on the system for easier localization of defects and track gradient measurement. Sophisticated assessment 


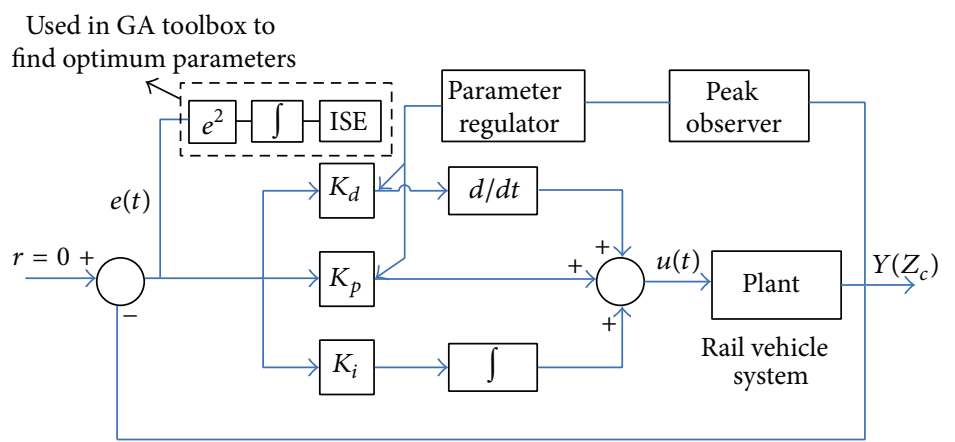

FIGURE 4: Block diagram of parameters adaptive PID controller.

software of KRAB computes measured data from the rail via fast Fourier transform (FFT) technique. KRAB can be equipped with either rollers or flanges, and flanges can be adapted for convenient tramway rail measurement. This system measures vertical and horizontal alignment, cant, and twist. In this study, measured vertical rail irregularities are used.

\section{Controllers Design}

As fit for the purpose of this study, different control algorithms are used on a quarter rail vehicle model as shown in Figure 1. Then, improvements of passenger comfort are compared. To suppress the vibrations on rail vehicle, first a conventional PID controller is designed. In order to increase the performance of this controller, the parameters adaptive method is used.

4.1. Conventional PID Controller. Due to the widespread use in industry and their simplicity, PID controllers are used in more than $95 \%$ of closed loop industrial processes [25]. Also, it is pretty probable that PID control will continue to be used in the future. Feedback has had a revolutionary influence in practically all areas where it has been used and will continue to do so. PID controller is perhaps the most basic form of feedback $[26,27]$.

In Figure 3, the PID controller is used as the compensator $(C)$, reference signal $(r)$, and output of this system $(Y$, vertical displacement of rail vehicle body " $Z_{c}$ ”). PID control algorithm and its closed loop block diagram are well known. For a conventional PID controller, the control input $u(t)$ is obtained as follows:

$$
u(t)=K_{p} e(t)+K_{i} \int_{0}^{t} e(t) d t+K_{d} \frac{d e(t)}{d t}
$$

where $e(t)$ is the control error; the controller parameters $K_{p}, K_{i}$, and $K_{d}$ are, respectively, proportional, integral, and derivative gains; and $C(s)$ is the transfer function of controller in Laplace form. Consider the following:

$$
C(s)=\frac{u(s)}{e(s)}=K_{p}+\frac{K_{i}}{s}+K_{d} s .
$$

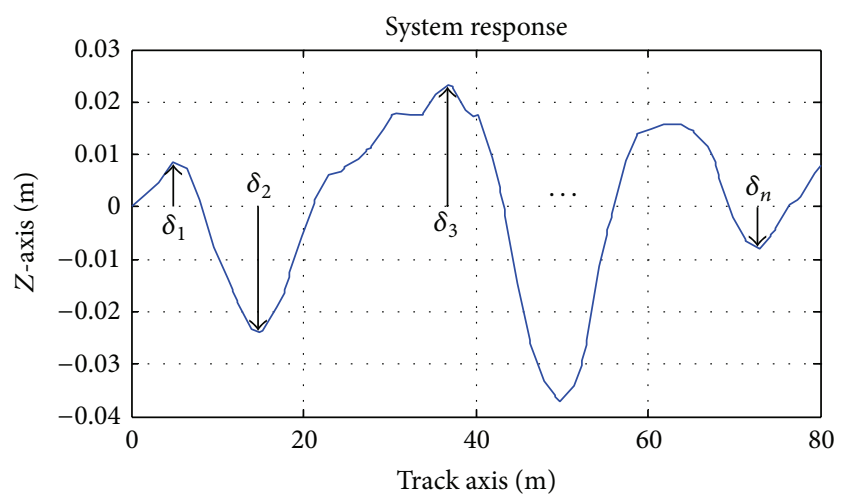

Figure 5: Peaks of the system response.

4.2. PID Controller with Parameters Adaptive Method. Sometimes using only simple PID controller does not present the effective response on system which has random and sufficient disturbances. Thus, some specific structured hybrid controllers are used that involve PID. In this study, a parameter adaptive method is used for tuning the PID parameters $\left(K_{p}, K_{i}\right.$, and $\left.K_{d}\right)$ in system model with different track types. It is well known that the proportional component of the PID has an important role on the performance of PID system to control vertical vibrations of vehicles. If the proportional control is too weak, the response will be slow, and if the integration component is too strong, the response will become unstable. So it is desirable to make further improvement on it which allows taking a larger value and reducing it gradually with time so as to increase the damping of the system and make the system more stable. By this way, an effective suppression and short settling time can be considered on displacement and acceleration responses of the system.

How to use parameters adaptive method for PID type fuzzy controller structure is described in detail by $\mathrm{Wu}$ and Mizumoto [28]. To suppress rail vehicle vibrations on a quarter model, this method was implemented by Metin and Güçlü [29]. It is known that the rail irregularities are the most important sources of vibrations which occur on rail vehicle body. In this study, two different rail irregularity effects are used to obtain disturbances effect. Amplitude of sinusoidal rail irregularity is $\left|a_{\text {sin }}\right|=0.02 \mathrm{~m}$ and maximum value of 


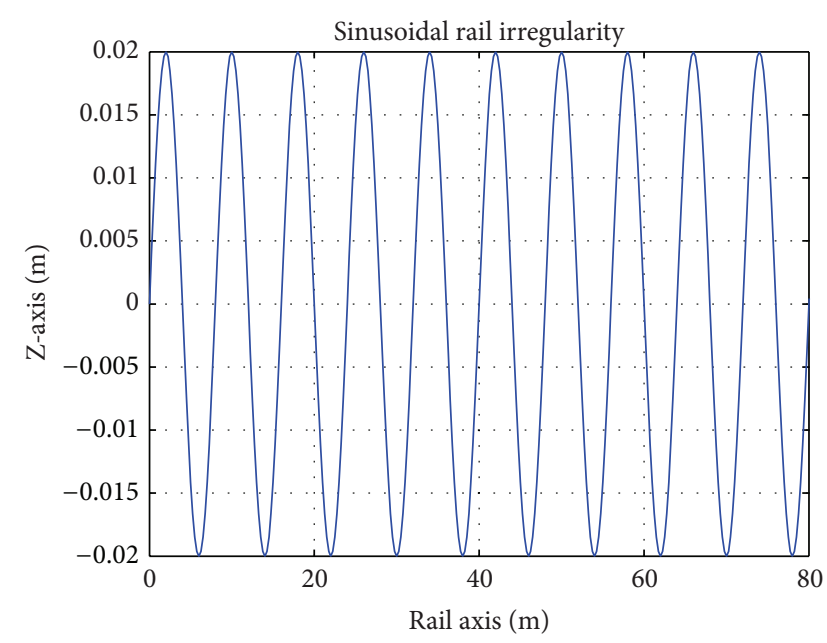

(a)

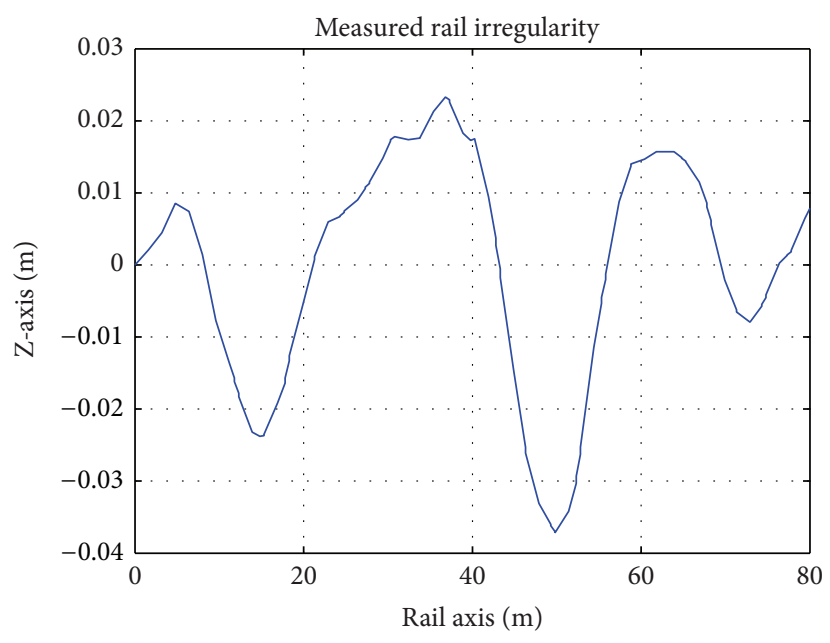

(b)

FIGURE 6: Sinusoidal (a) and measured real (b) rail irregularity.
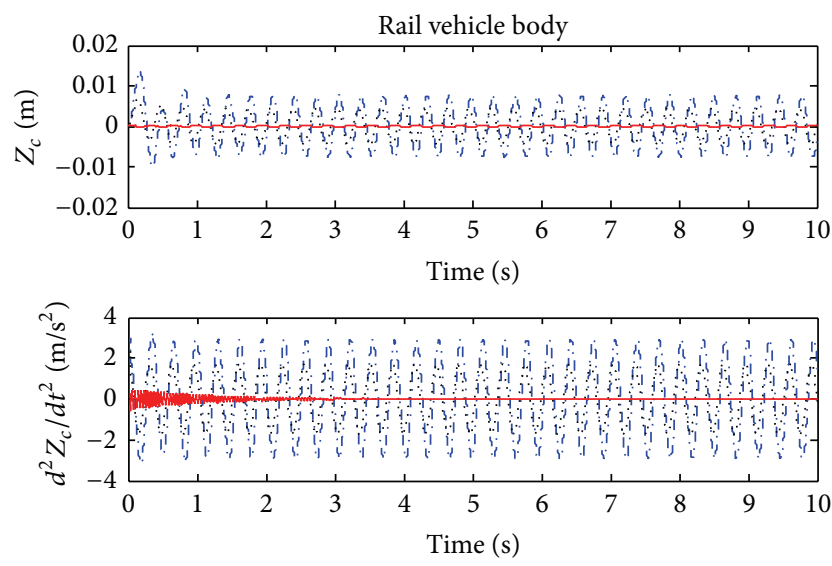

-..- Uncontrolled

— Adaptive PID

FIGURE 7: Uncontrolled and controlled rail vehicle body vibrations for sinusoidal rail irregularity $\left(M_{c}=8400 \mathrm{~kg}\right)$.

random rail irregularity is $\left|a_{\text {ran }}\right|=0.037 \mathrm{~m}$. Peak observer detects peak values of rail vehicle vibrations and sends values to parameters regulator, $G_{p}$ and $G_{d}$. $G_{p}$ and $G_{d}$ are new parameters which regulate $K_{p}$ and $K_{d}$ online, respectively, whereas increasing the value of $K_{p}$ and $K_{d}$ will increase the proportional control component; thus the reaction of the control system against the error will be sped up and vibrations will be suppressed effectively.

The weighted role of " $I$ " term in PID control is known as to reduce the steady-state error of systems. A remarkable steady-state error does not occur in this study. So, there is no need for online adjustment of the term $K_{i}$ by parameter regulator. Also, this process needs additional functions which complicate the controller configuration unnecessarily.

Motivated by this idea, a parameters adaptive PID controller is designed. This controller is composed of a PID controller, a peak observer, and a parameter regulator (Figure 4).
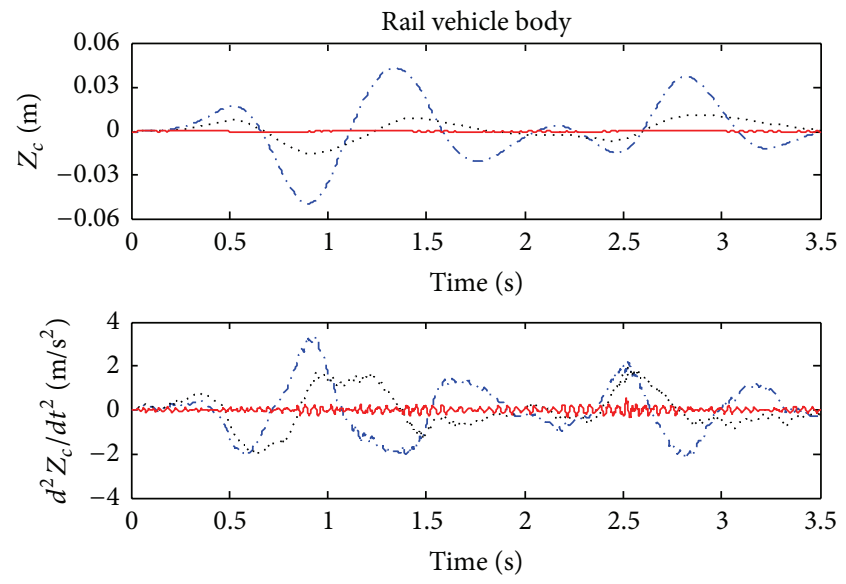

$$
\begin{aligned}
& \text {..- Uncontrolled } \quad \text { Adaptive PID } \\
& \text {.... PID }
\end{aligned}
$$

FIGURE 8: Uncontrolled and controlled rail vehicle body vibrations for real rail irregularity $\left(M_{c}=8400 \mathrm{~kg}\right)$.

The peak observer keeps watching on the system output, transmits a signal at each peak time, and measures the absolute peak value $\left(\delta_{1}-\delta_{n}\right)$ (Figure 5). The parameter regulator tunes the controller parameters $K_{p}$ and $K_{d}$ simultaneously at each peak time signal according to the peak value at that time. The algorithm of tuning the scaling constants and the derivative gain are as follows:

$$
\begin{array}{cc}
K_{p}=\frac{K_{p s}}{\delta_{k} G_{p}}, \quad K_{d}=\frac{K_{d s}}{\delta_{k} G_{d}} \quad \text { for } \delta_{k} \geq 0,001 \mathrm{~m}, \\
K_{p}=K_{p s}, \quad K_{d}=K_{d s} \quad \text { for } \delta_{k}<0,001 \mathrm{~m},
\end{array}
$$

where $K_{p s}$ and $K_{d s}$ are the initial values of $K_{p}$ and $K_{d}$, respectively. $\delta_{k}$ is the absolute peak value at the peak time $t_{k}(k=1,2,3, \ldots)$ for $\delta_{k} \geq 0,0001 \mathrm{~m} . G_{p}$ and $G_{d}$ are additional scaling factors of peak values for parameters 
TABLE 1: Maximum values and ranges of vibrations for sinusoidal rail irregularity.

\begin{tabular}{lcc}
\hline $\begin{array}{l}M_{c}=8400 \mathrm{~kg} \\
\text { rail vehicle body }\end{array}$ & Displacement $(\mathrm{m})$ & Acceleration $\left(\mathrm{m} / \mathrm{s}^{2}\right)$ \\
\hline $\begin{array}{l}\text { Maximum values } \\
\text { Uncontrolled }\end{array}$ & 0,01391 & 3,222 \\
PID & 0,006705 & 2,357 \\
Adaptive PID & $6,589 e-005$ & 0,6163 \\
Ranges & & \\
Uncontrolled & 0,02358 & 6,387 \\
PID & 0,01112 & 4,069 \\
Adaptive PID & $1,274 e-004$ & 1,095 \\
\hline
\end{tabular}

TABLE 2: Maximum values and ranges of vibrations for real rail irregularity.

\begin{tabular}{lcc}
\hline $\begin{array}{l}M_{c}=8400 \mathrm{~kg} \\
\text { rail vehicle body }\end{array}$ & Displacement $(\mathrm{m})$ & Acceleration $\left(\mathrm{m} / \mathrm{s}^{2}\right)$ \\
\hline $\begin{array}{l}\text { Maximum values } \\
\text { Uncontrolled }\end{array}$ & 0,04974 & 3,314 \\
PID & 0,01558 & 1,997 \\
Adaptive PID & $4,545 e-005$ & 0,575 \\
Ranges & & \\
Uncontrolled & 0,09314 & 5,493 \\
PID & 0,02705 & 3,942 \\
Adaptive PID & $8,495 e-005$ & 0,9261 \\
\hline
\end{tabular}

adaptive PID controller. Values of $K_{p}, K_{i}$, and $K_{d}$ are fixed for both controllers. These values are established by trial and error in this study. $G_{p}$ and $G_{d}$ scaling factor values are determined with ISE performance index by the use of genetic algorithm toolbox in Matlab under a real rail irregularity effect.

\section{Results}

The level of comfort is related to essential performance requirements. How safe the ride is mainly depends on the displacement response, while the level of comfort depends on the acceleration response. Controllers are designed to take into account both two responses. New parameters derived from adaptive method are determined using genetic algorithm toolbox according to the formula ISE (integral of square error). These parameter values of controllers are given in the Appendix. ISE value of controller is $2,486 \cdot 10^{-11}$. Consider the following:

$$
S_{\text {ISE }}=\int_{0}^{10} e^{2}(t) d t .
$$

After obtaining the conventional PID and parameters adaptive PID controller, we will compare the two controllers to illustrate the performance of closed loop suspension system in time and frequency domain. By the simulation, passive responses of rail vehicle, responses of conventional
TABLE 3: Maximum values and ranges of vibrations under varying loading for sinusoidal rail irregularity.

\begin{tabular}{lcc}
\hline $\begin{array}{l}M_{c}=7980 \mathrm{~kg} \\
\text { rail vehicle body }\end{array}$ & Displacement $(\mathrm{m})$ & Acceleration $\left(\mathrm{m} / \mathrm{s}^{2}\right)$ \\
\hline Maximum values & & \\
Uncontrolled & 0,01426 & 3,428 \\
PID & 0,006945 & 2,47 \\
Adaptive PID & $6,504 e-005$ & 0,5947 \\
Ranges & & \\
Uncontrolled & 0,02472 & 6,739 \\
PID & 0,01156 & 4,266 \\
Adaptive PID & $1,245 e-004$ & 1,045 \\
\hline$M_{c}=8820 \mathrm{~kg}$ & Displacement $(\mathrm{m})$ & Acceleration $\left(\mathrm{m} / \mathrm{s}^{2}\right)$ \\
rail vehicle body & & 3,036 \\
\hline Maximum values & 0,01357 & 2,254 \\
Uncontrolled & 0,006481 & 0,6376 \\
PID & $6,677 e-005$ & 6,063 \\
Adaptive PID & & 3,892 \\
Ranges & 0,02251 & 1,151 \\
Uncontrolled & 0,0107 & \\
PID & $1,304 e-004$ & \\
Adaptive PID & & \\
\hline
\end{tabular}

TABLE 4: Maximum values and ranges of vibrations under varying loading for real rail irregularity.

\begin{tabular}{lcc}
\hline $\begin{array}{l}M_{c}=7980 \mathrm{~kg} \\
\text { rail vehicle body }\end{array}$ & Displacement $(\mathrm{m})$ & Acceleration $\left(\mathrm{m} / \mathrm{s}^{2}\right)$ \\
\hline Maximum values & & \\
Uncontrolled & 0,04961 & 3,333 \\
PID & 0,01604 & 2,062 \\
Adaptive PID & $4,494 e-005$ & 0,5422 \\
Ranges & & \\
Uncontrolled & 0,09159 & 5,536 \\
PID & 0,0277 & 4,089 \\
Adaptive PID & $8,251 e-005$ & 0,8533 \\
\hline$M_{c}=8820 \mathrm{~kg}$ & Displacement $(\mathrm{m})$ & Acceleration $\left(\mathrm{m} / \mathrm{s}^{2}\right)$ \\
rail vehicle body & & \\
\hline Maximum values & 0,04981 & 3,288 \\
Uncontrolled & 0,01514 & 1,935 \\
PID & $4,61 e-005$ & 0,609 \\
Adaptive PID & & 5,442 \\
Ranges & 0,0945 & 3,804 \\
Uncontrolled & 0,02628 & 1,006 \\
PID & $8,88 e-005$ & \\
Adaptive PID & & \\
\hline
\end{tabular}

PID controller, and responses of parameters adaptive PID controller are compared in Figures 7-12. In these figures, the blue dotted lines, black dotted lines, and red solid lines are the responses of the passive system (uncontrolled), conventional PID controller (PID), and parameters adaptive PID 

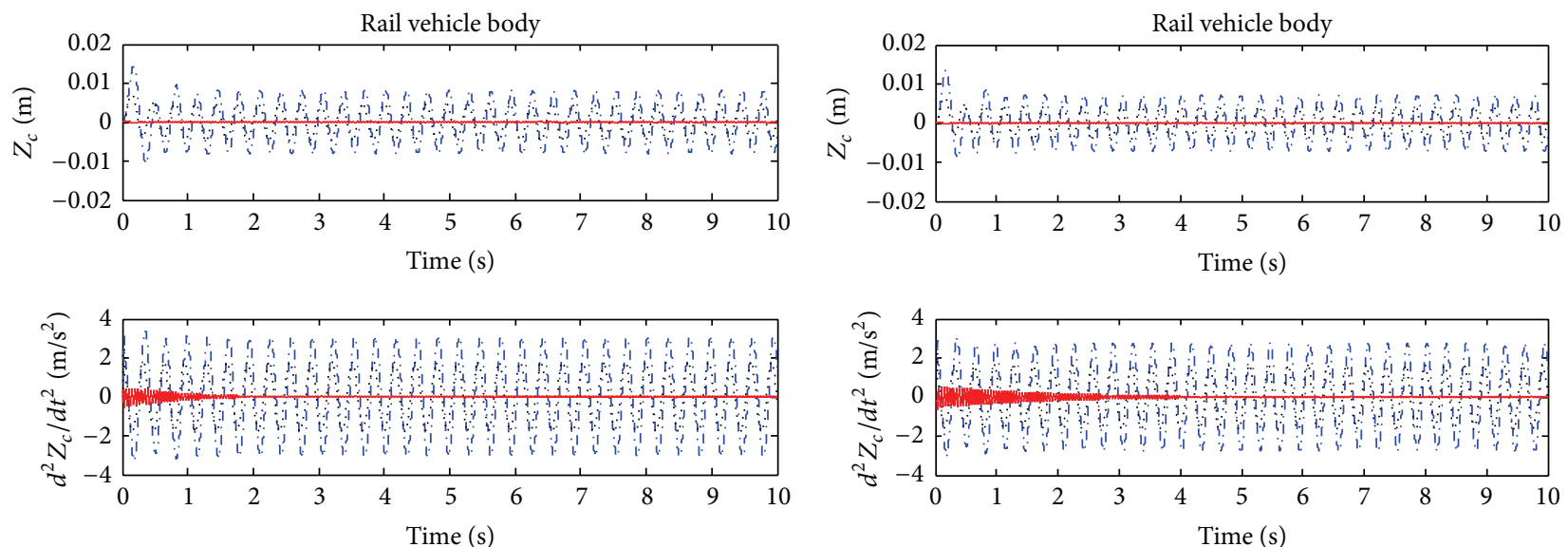

-.. Uncontrolled

Adaptive PID PID

(a) $M_{c}=7980 \mathrm{~kg}$

-..- Uncontrolled _ Adaptive PID

(b) $M_{c}=8820 \mathrm{~kg}$

FIGURE 9: Rail vehicle body vibrations for body mass uncertainty for sinusoidal rail irregularity.
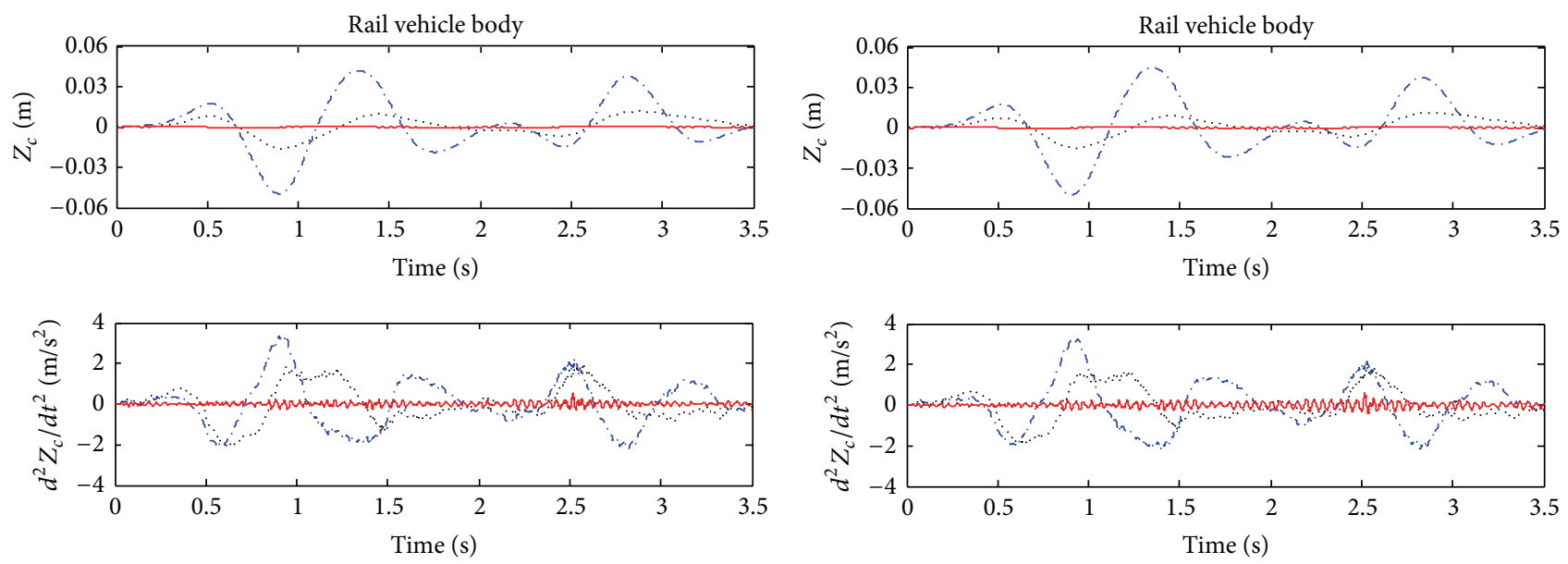

-... Uncontrolled $\quad$ Adaptive PID
.... PID

(a) $M_{c}=7980 \mathrm{~kg}$

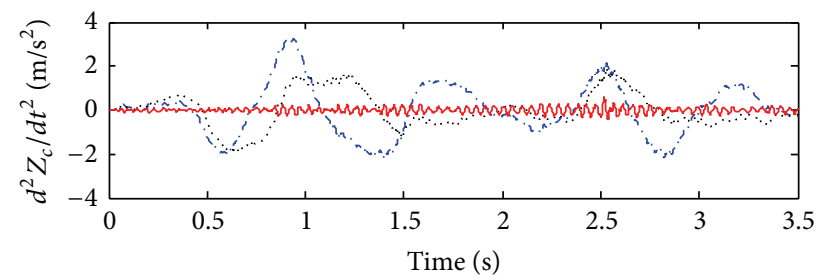

...- Uncontrolled

— Adaptive PID

(b) $M_{c}=8820 \mathrm{~kg}$

FIGURE 10: Rail vehicle body vibrations for body mass uncertainty for real rail irregularity.

controllers (adaptive PID), respectively. From these figures, we can see that the parameters adaptive PID controller yields the least value of rail vehicle body displacements and accelerations in time and frequency domain, compared with the passive system and the conventional PID controller, which clearly shows that an improved ride comfort has been achieved.

In order to evaluate the rail vehicle body vibrations, with respect to ride comfort and safety, we give two different disturbance signals as follows to clarify the effectiveness of our new designed parameters adaptive controller (Figure 6). The sinusoidal rail irregularity describes the collapse of the railway substructures with time; period $(y)$ and amplitude $(a)$ of generated sinus function are $8 \mathrm{~m}$ and $0.02 \mathrm{~m}$, respectively (Figure 6(a)). In Figure 6(b), measured real rail irregularity for a certain track $(80 \mathrm{~m})$ is shown. Maximum urban transportation speed $(90 \mathrm{~km} / \mathrm{h})$ of rail vehicle is used for all simulations.

Figures 7 and 8 demonstrate the rail vehicle body displacements and accelerations for passive, PID controlled, and parameters adaptive PID controlled systems for $8400 \mathrm{~kg}$ body mass under sinusoidal and measured real rail irregularities, respectively.

Tables 1 and 2 represent the maximum values and ranges of rail vehicle $\left(M_{c}=8400 \mathrm{~kg}\right)$ vibrations for the same cases. Range is the meaning of difference between maximum and minimum values.

We can clearly see that the values of the body displacement and acceleration with the parameters adaptive controller are less than that with the conventional PID controller for both irregularity cases (Figures 7 and 8 and Tables 1 and 2). 

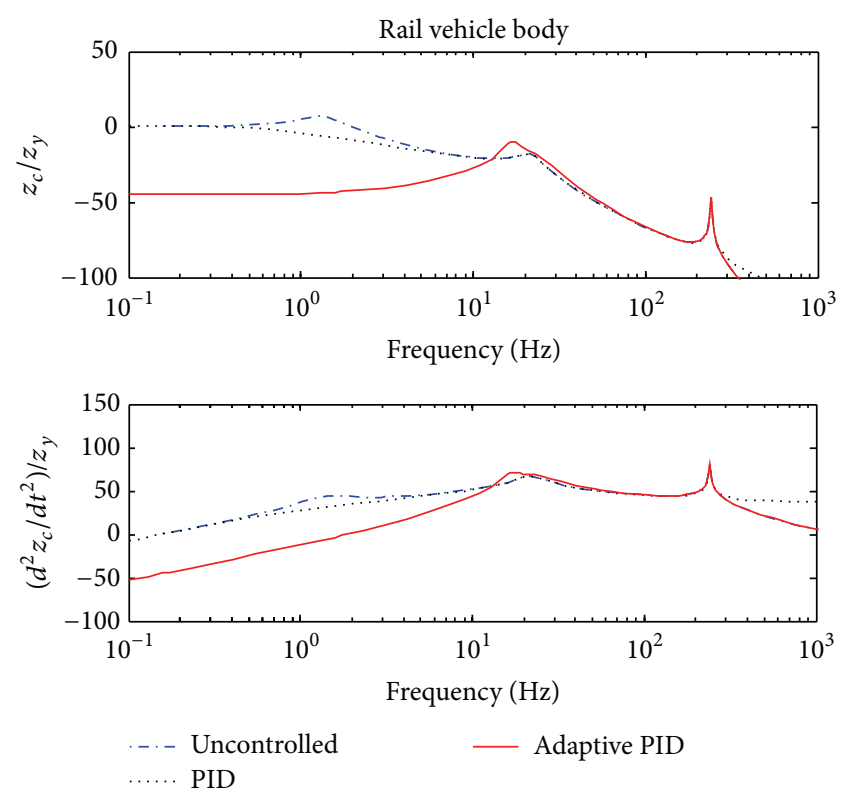

FIGURE 11: Uncontrolled and controlled rail vehicle body responses in frequency domain $\left(M_{c}=8400 \mathrm{~kg}\right)$.

TABLE 5: Maximum values of vibrations at first peak $(1,286 \mathrm{~Hz})$.

\begin{tabular}{lcc}
\hline $\begin{array}{l}M_{c}=8400 \mathrm{~kg} \\
\text { rail vehicle body }\end{array}$ & Displacement & Acceleration \\
\hline $\begin{array}{l}\text { Maximum values } \\
\text { Uncontrolled }\end{array}$ & 6,873 & \\
PID & $-4,96$ & 44,56 \\
Adaptive PID & $-43,89$ & 32,67 \\
\hline
\end{tabular}

Robustness of controllers is examined under different rail irregularities and a combination of varying loading conditions. To test robustness of controllers for uncertainty of rail vehicle body mass $( \pm 5 \%)$ because of passengers' load, a set of simulations is carried out. Within the framework of these objectives, the frequency responses are investigated in addition to the time domain responses (Figures 9-12).

Figures 9 and 10 represent the responses of rail vehicle body vibrations for different body masses $(7980 \mathrm{~kg}$ and $8820 \mathrm{~kg}$ ) under sinusoidal and real rail irregularities, respectively. According to these figures, superior performances of parameters adaptive controller can be seen for both rail disturbances. These responses of the controllers indicate the stability of closed loop systems for body mass uncertainty and varying rail irregularity.

Table 3 demonstrates that when the rail vehicle mass decreases, the passive displacement increases for sinusoidal rail irregularity. PID controller application exhibits a parallel behavior to passive. However, rail vehicle body vibration amplitudes are efficiently suppressed by using parameters adaptive PID controller, while passive response increases. This event demonstrates the superiority of the parameters adaptive controller.
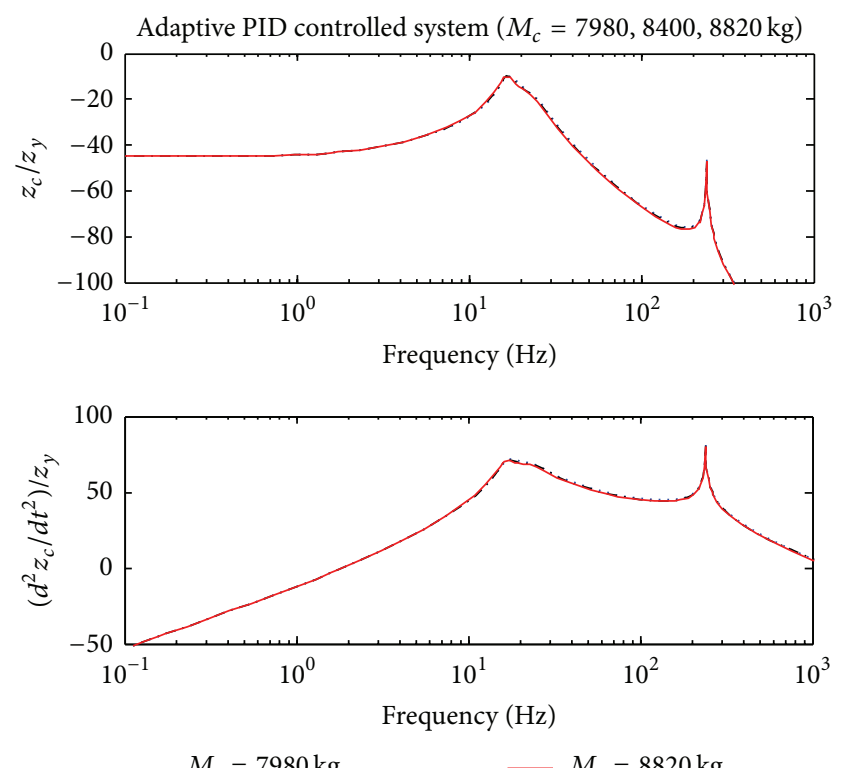

$$
\begin{aligned}
& \ldots \ldots M_{c}=7980 \mathrm{~kg} \\
& \ldots-M_{c}=8400 \mathrm{~kg}
\end{aligned}
$$

FIGURE 12: Frequency responses of rail vehicle body for body mass uncertainty.

TABLE 6: Maximum values of vibrations at $16,5 \mathrm{~Hz}$.

\begin{tabular}{ccc}
\hline Rail vehicle body & Displacement & Acceleration \\
\hline Maximum values & & \\
$7980 \mathrm{~kg}$ & $-9,832$ & 71,73 \\
$8400 \mathrm{~kg}$ & $-9,998$ & 71,25 \\
$8820 \mathrm{~kg}$ & $-10,14$ & 70,8 \\
\hline
\end{tabular}

Table 4 demonstrates that rail vehicle body vibration amplitudes are suppressed efficiently by using parameters adaptive PID controller. These results reveal the superior performances of adaptive PID controller for both rail irregularities.

Figure 11 demonstrates the uncontrolled and controlled rail vehicle body responses in frequency domain for average loading of rail vehicle $\left(M_{c}=8400 \mathrm{~kg}\right)$. In this figure, red solid line is the responses of rail vehicle body vertical displacement and acceleration with the parameters adaptive PID controller. We can clearly see that the value of the body displacement and acceleration with the parameters adaptive PID controller is much less than that with conventional PID controller and the passive system. These results can effectively achieve desired ride comfort. It is well known from the ISO2631 that the human body is much sensitive to vibrations between $4 \mathrm{~Hz}$ and $8 \mathrm{~Hz}$ in the vertical direction. Consequently, the improvement of vibration isolation of 4$8 \mathrm{~Hz}$ is very significant.

Table 5 represents the maximum values of rail vehicle vibrations at first peak $(1,286 \mathrm{~Hz})$ for uncontrolled and controlled cases.

In this study, 3 different rail vehicle body masses $\left(M_{c}=\right.$ 7980,8400 , and $8820 \mathrm{~kg}$ ) which represent varying loading conditions of body are used to examine robustness 
TABLE 7

\begin{tabular}{lll}
\hline Mass parameters & Stiffness parameters & $\begin{array}{l}\text { Damping } \\
\text { parameters }\end{array}$ \\
\hline$M_{c}=8400 \mathrm{~kg}$ & $k_{11}=12200000 \mathrm{~N} / \mathrm{m}$ & $c_{11}=4000 \mathrm{Ns} / \mathrm{m}$ \\
$M_{b}=653,75 \mathrm{~kg}$ & $k_{12}=12200000 \mathrm{~N} / \mathrm{m}$ & $c_{12}=4000 \mathrm{Ns} / \mathrm{m}$ \\
$J_{b}=1121 \mathrm{kgm}^{2}$ & $k_{2}=320000 \mathrm{~N} / \mathrm{m}$ & $c_{2}=20000 \mathrm{Ns} / \mathrm{m}$ \\
$M_{w 1}=453,25 \mathrm{~kg}$ & $k_{h 1}=1015549000 \mathrm{~N} / \mathrm{m}$ & \\
$M_{w 2}=453,25 \mathrm{~kg}$ & $k_{h 2}=1015549000 \mathrm{~N} / \mathrm{m}$ & \\
\hline Other parameters & PID controller & Adaptive PID \\
& parameters & parameters \\
\hline$L_{a}=0,9 \mathrm{~m}$ & $K_{p}=6,27 \cdot 10^{5}$ & $G_{p}=0.55$ \\
$F=69825 \mathrm{~N}$ & $K_{i}=100$ & $G_{d}=52.8$ \\
$C_{h}=1 \cdot 10^{11} \mathrm{~N} / \mathrm{m}^{3 / 2}$ & $K_{d}=120$ & \\
\hline
\end{tabular}

of controllers. In case of $M_{c}=8400 \mathrm{~kg}$, eigenvector of system is $\left[\begin{array}{lllll}0.98 & 21 & 30.8 & 239.7 & 239.7\end{array}\right]^{T}$. For second case of simulations $\left(M_{c}=7980 \mathrm{~kg}\right)$, eigenvector of system is $\left[\begin{array}{lllll}1 & 21 & 30.8 & 239.7 & 239.7\end{array}\right]^{T}$. For the last simulation case $\left(M_{c}=8820 \mathrm{~kg}\right)$, eigenvector of system is $\left[\begin{array}{lllll}0.95 & 21 & 30.8 & 239.7 & 239.7\end{array}\right]^{T}$. Eigenvalue analysis shows that the first eigenvalue belongs to rail vehicle body mass, predominantly. In Figure 11, the first peak of uncontrolled system is suppressed successfully by parameters adaptive PID controller. The use of parameters adaptive method on PID controller demonstrates the superior performance to control vibrations of rail vehicle body in time and frequency domain.

Frequency responses of rail vehicle body for rail vehicle body mass uncertainty $\left( \pm 5 \% M_{c}\right)$ are shown in Figure 12 . This figure and Table 6 demonstrate that frequency responses of rail vehicle body do not change significantly for varying loading. It shows the controllers protecting their robustness for body mass changes $\left( \pm 5 \% M_{c}\right)$.

\section{Conclusions}

In this study, a quarter rail vehicle model, which is designed as a 5 degrees of freedom system, is examined under combinations of varying loading and rail irregularities. To control the vertical vibrations of rail vehicle body, the performances of a conventional PID and a parameters adaptive PID controller are compared. For controlled and uncontrolled cases, displacement and acceleration responses of rail vehicle body in time and frequency domains are shown. In the case of parameters adaptive PID controller, $K_{p}$ and $K_{d}$ parameters are tuned online under varying rail irregularities. Thus, an original study is presented by the use of a heuristic method. The controllers protect their robustness for varying loading conditions. The simulation results indicate that the adaptive PID substantially improves the performance of the control system. It has presented the simulation results to demonstrate the high performance of the proposed PID controller with parameters adaptive method.

For further studies, parameters adaptive PID controller performances can be compared with parameters adaptive fuzzy controller to improve the ride comfort of rail vehicles. On the other hand, performance of parameters adaptive PID controller can be investigated to suppress the lateral movements of rail vehicles by using a detailed lateral dynamic model which contains wheel-rail contact forces and creepages.

\section{Appendix}

Parameters of the rail vehicle $[30,31]$; see Table 7.

Mass, damping, and stiffness matrices of the system:

$$
\begin{aligned}
& M=\left[\begin{array}{ccccc}
M_{c} & 0 & 0 & 0 & 0 \\
0 & M_{b} & 0 & 0 & 0 \\
0 & 0 & J_{b} & 0 & 0 \\
0 & 0 & 0 & M_{w 1} & 0 \\
0 & 0 & 0 & 0 & M_{w 2}
\end{array}\right] \\
& C=\left[\begin{array}{ccccc}
c_{2} & -c_{2} & 0 & 0 & 0 \\
-c_{2} & \left(c_{2}+c_{11}+c_{12}\right) & \left(c_{11}-c_{12}\right) L_{a} & -c_{11} & -c_{12} \\
0 & \left(c_{11}-c_{12}\right) L_{a} & \left(c_{11}+c_{12}\right) L_{a}^{2} & -L_{a} c_{11} & L_{a} c_{12} \\
0 & -c_{11} & -L_{a} c_{11} & c_{11} & 0 \\
0 & -c_{12} & L_{a} c_{12} & 0 & c_{12}
\end{array}\right], \\
& K=\left[\begin{array}{ccccc}
k_{2} & -k_{2} & 0 & 0 & 0 \\
-k_{2} & \left(k_{2}+k_{11}+k_{12}\right) & \left(k_{11}-k_{12}\right) L_{a} & -k_{11} & -k_{12} \\
0 & \left(k_{11}-k_{12}\right) L_{a} & \left(k_{11}+k_{12}\right) L_{a}^{2} & -L_{a} k_{11} & L_{a} k_{12} \\
0 & -k_{11} & -L_{a} k_{11} & \left(k_{11}+k_{h 1}\right) & 0 \\
0 & -k_{12} & L_{a} k_{12} & 0 & \left(k_{12}+k_{h 2}\right)
\end{array}\right] .
\end{aligned}
$$




\section{Conflict of Interests}

The authors declare that there is no conflict of interests regarding the publication of this paper.

\section{References}

[1] Y. Q. Sun and M. Dhanasekar, "A dynamic model for the vertical interaction of the rail track and wagon system," International Journal of Solids and Structures, vol. 39, no. 5, pp. 1337-1359, 2002.

[2] H. H. Jenkins, J. E. Stephenson, G. A. Clayton, G. W. Morland, and D. Lyon, "The effect of track and vehicle parameters on wheel/rail vertical dynamic forces," Railway Engineering Journal, vol. 3, no. 1, pp. 2-16, 1974.

[3] C. Esveld, Modern Railway Track, MRT Productions, Zaltbommel, The Netherlands, 2001.

[4] R. V. Dukkipati and R. Dong, "The dynamic effects of conventional freight car running over a dipped-joint," Vehicle System Dynamics, vol. 31, no. 2, pp. 95-111, 1999.

[5] X. Lei and N.-A. Noda, "Analyses of dynamic response of vehicle and track coupling system with random irregularity of track vertical profile," Journal of Sound and Vibration, vol. 258, no. 1, pp. 147-165, 2002.

[6] E. Foo and R. M. Goodall, "Active suspension control of flexiblebodied railway vehicles using electro-hydraulic and electromagnetic actuators," Control Engineering Practice, vol. 8, no. 5, pp. 507-518, 2000.

[7] R. M. Goodall and W. Kortüm, "Mechatronic developments for railway vehicles of the future," Control Engineering Practice, vol. 10, no. 8, pp. 887-898, 2002.

[8] R. Güçlü, "Active control of seat vibrations of a vehicle model using various suspension alternatives," Turkish Journal of Engineering and Environmental Sciences, vol. 27, no. 6, pp. 361-373, 2003.

[9] M. Ahmadian and A. Mohan, "Semiactive control of hunting stability in rail vehicles," in Proceedings of the ASME International Mechanical Engineering Congress and Exposition (IMECE '05), pp. 63-68, Orlando, Fla, USA, November 2005.

[10] N. Yagiz and A. Gursel, "Active suspension control of a railway vehicle with a flexible body," International Journal of Vehicle Autonomous Systems, vol. 3, no. 1, pp. 80-95, 2005.

[11] Y.-C. Lin, C.-L. Lin, and N.-C. Shieh, "An evolutionary approach to active suspension design of rail vehicles," Journal of the Chinese Institute of Engineers, vol. 29, no. 5, pp. 909-915, 2006.

[12] A. Pacchioni, R. M. Goodall, and S. Bruni, "Active suspension for a two-axle railway vehicle," Vehicle System Dynamics, vol. 48, no. 1, pp. 105-120, 2010.

[13] A. Orvnäs, S. Stichel, and R. Persson, "Ride comfort improvements in a high-speed train with active secondary suspension," Journal of Mechanical Systems for Transportation and Logistics, vol. 3, no. 1, pp. 206-215, 2010.

[14] A. Orvnäs, S. Stichel, and R. Persson, "Active lateral secondary suspension with $\mathrm{H}_{\infty}$ control to improve ride comfort: simulations on a full-scale model," Vehicle System Dynamics, vol. 49, no. 9, pp. 1409-1422, 2011.

[15] S. Bruni, J. Vinolas, M. Berg, O. Polach, and S. Stichel, "Modelling of suspension components in a rail vehicle dynamics context," Vehicle System Dynamics, vol. 49, no. 7, pp. 1021-1072, 2011.
[16] W. Sun, H. Gao, and O. Kaynak, "Finite frequency $\mathrm{H}_{\infty}$ control for vehicle active suspension systems," IEEE Transactions on Control Systems Technology, vol. 19, no. 2, pp. 416-422, 2011.

[17] W. Sun, Y. Zhao, J. Li, L. Zhang, and H. Gao, "Active suspension control with frequency band constraints and actuator input delay," IEEE Transactions on Industrial Electronics, vol. 59, no. 1, pp. 530-537, 2012.

[18] J. J. Lozoya-Santos, R. Morales-Menendez, and R. A. Ramírez Mendoza, "Control of an automotive semi-active suspension," Mathematical Problems in Engineering, vol. 2012, Article ID 218106, 21 pages, 2012.

[19] Y.-J. Liang and S.-L. Wu, "Optimal vibration control for tracked vehicle suspension systems," Mathematical Problems in Engineering, vol. 2013, Article ID 178354, 7 pages, 2013.

[20] M. V. C. Rao and V. Prahlad, "A tunable fuzzy logic controller for vehicle-active suspension systems," Fuzzy Sets and Systems, vol. 85, no. 1, pp. 11-21, 1997.

[21] M. Metin, R. Guclu, H. Yazici, and N. S. Yalcin, "A comparison of control algorithms for a half rail vehicle model under track irregularity effect," in Mechanics Conference and 100th Anniversary of Engineering of Science and Mechanics Department Virginia Polytechnic and State University, Blacksburg, Va, USA, 2008.

[22] R. Guclu and M. Metin, "Fuzzy logic control of vibrations of a light rail transport vehicle in use in Istanbul traffic," Journal of Vibration and Control, vol. 15, no. 9, pp. 1423-1440, 2009.

[23] M. Metin and R. Guclu, "Active vibration control with comparative algorithms of half rail vehicle model under various track irregularities," Journal of Vibration and Control, vol. 17, no. 10, pp. 1525-1539, 2011.

[24] Homepage of Komercni Zeleznicni Vyzkum (KZV), spol. s r.o., http://kzv.cz/English/krab.php.

[25] K. J. Astrom and T. H. Hagglund, "New tuning methods for PID controller," in Proceeding of the 3rd European Control Conference, Rome, Italy, 1995.

[26] M. Araki, "PID control," in Control Systems, Robotics, and Automation, vol. 2, 1992.

[27] K. J. Åström and T. Hägglund, "The future of PID control," Control Engineering Practice, vol. 9, no. 11, pp. 1163-1175, 2001.

[28] Z. Q. Wu and M. Mizumoto, "PID type fuzzy controller and parameters adaptive method," Fuzzy Sets and Systems, vol. 78, no. 1, pp. 23-35, 1996.

[29] M. Metin and R. Güçlü, "Vibrations control of light rail transportation vehicle via PID type fuzzy controller using parameters adaptive method," Turkish Journal of Electrical Engineering and Computer Sciences, vol. 19, no. 5, pp. 807-816, 2011.

[30] S. Iwnicki, "The Manchester benchmarks for rail simulatorsan introduction," Vehicle System Dynamics, vol. 29, supplement 1, pp. 717-722, 1998.

[31] S. Iwnick, "Manchester benchmarks for rail vehicle simulation," Vehicle System Dynamics, vol. 30, no. 3-4, pp. 295-313, 1998. 


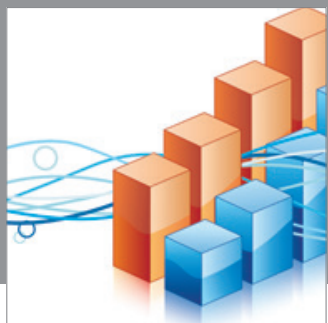

Advances in

Operations Research

mansans

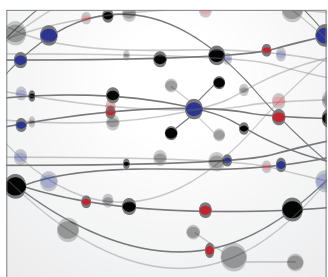

The Scientific World Journal
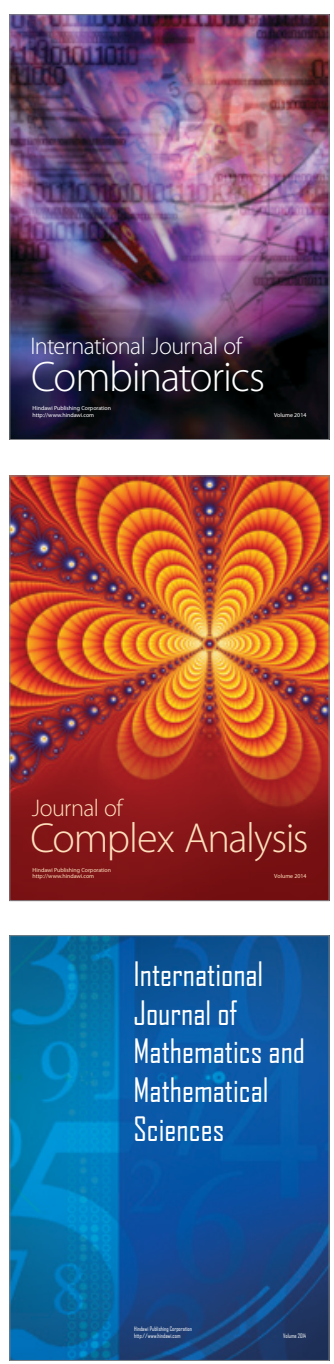
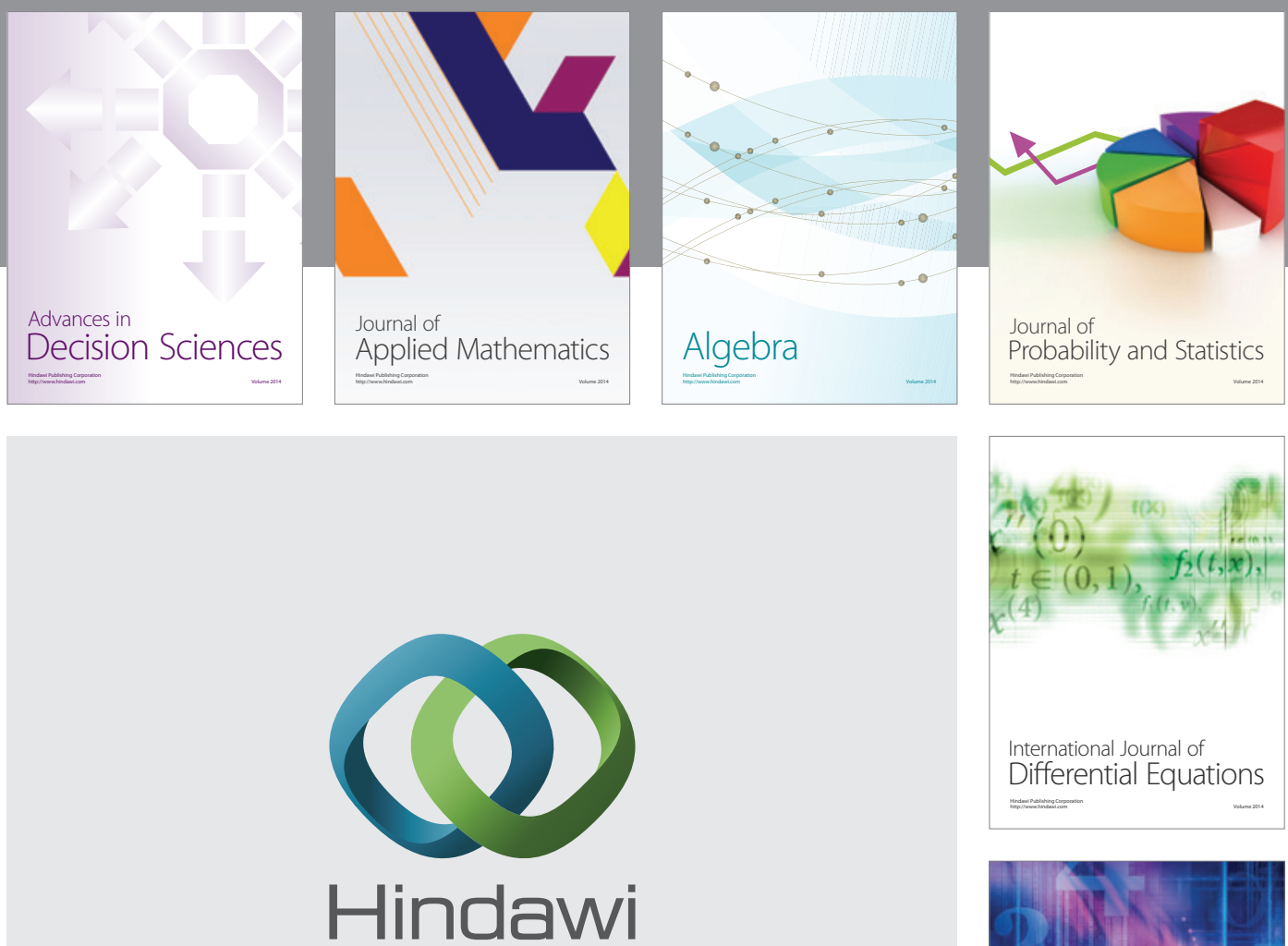

Submit your manuscripts at http://www.hindawi.com
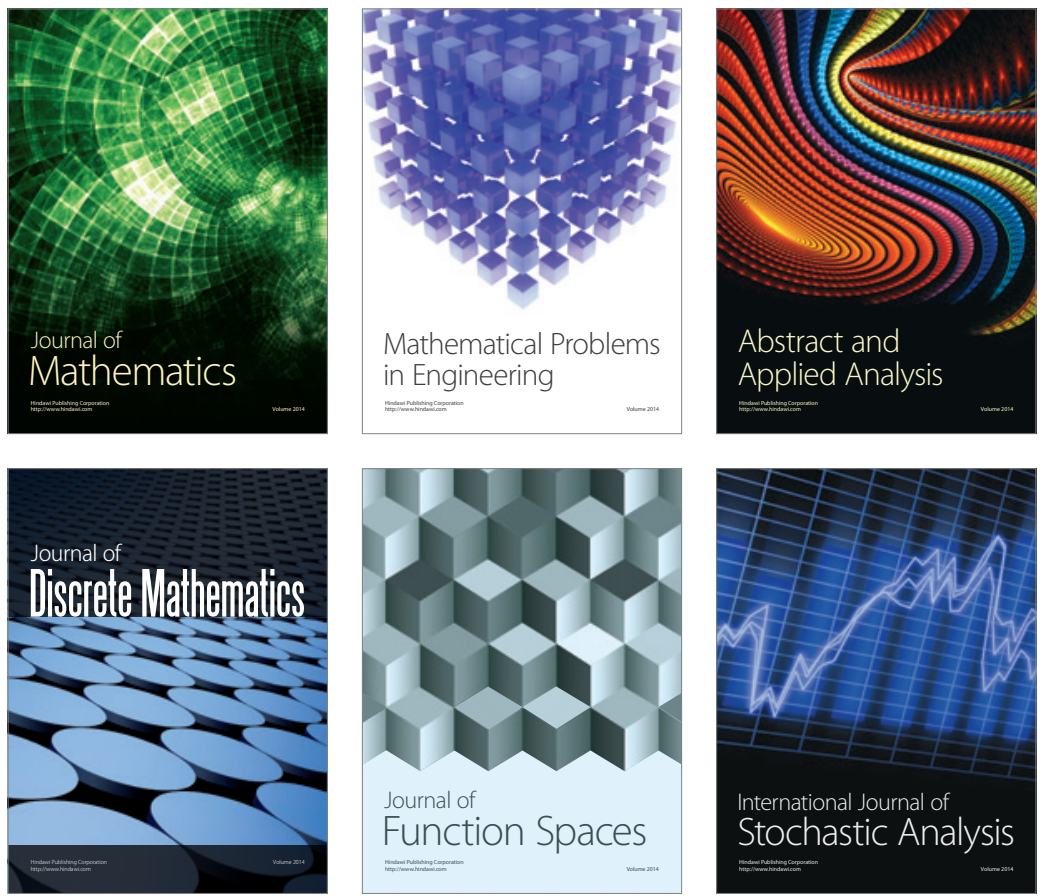

Journal of

Function Spaces

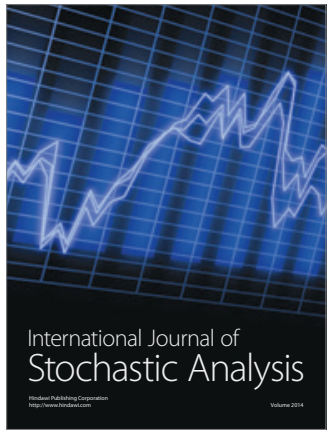

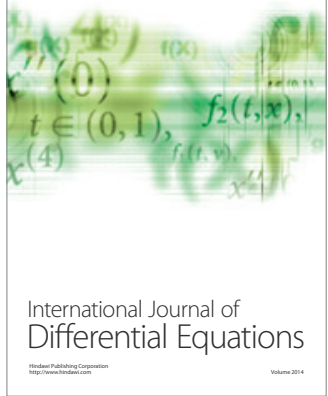
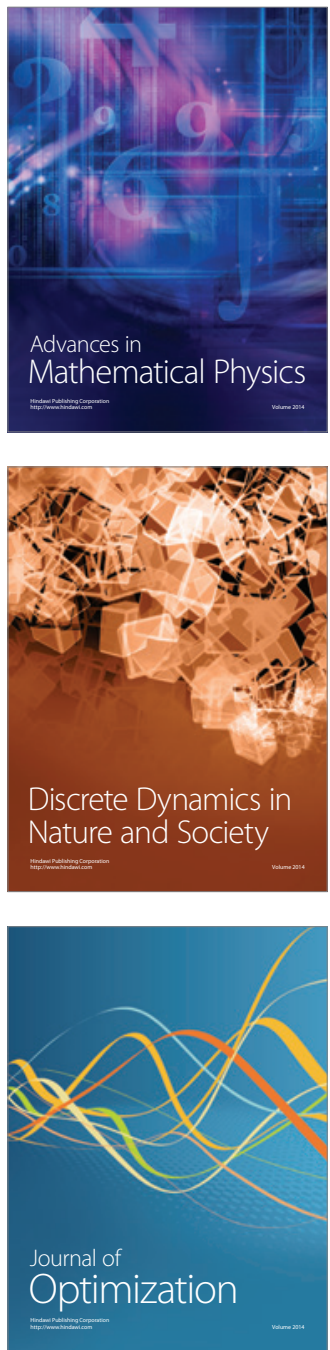